\title{
Realidade virtual e a medicina
}

\section{Edna Frasson de Souza Montero Dinamar José Zanchet}

O termo realidade virtual (RV) foi criado para definir os mundos virtuais desenvolvidos com o uso de alta tecnologia para convencer o usuário que ele se encontra em outra realidade. Pode-se dizer que se trata de uma avançada interface homem-máquina que simula um ambiente real. Refere-se também a uma experiência de imersão e interação baseadas em imagens gráficas tridimensionais, geradas por computador.

A RV envolve três conceitos: 1) Imersão mental: que acontece quando se olha uma imagem tridimensional em uma tela e imersão física: que requer o uso de periféricos sofisticados como capacetes estereoscópicos e datagloves, que dão a impressão de se ter passado através do espelho da tela. 2) Navegação que é a capacidade de se mover e de se encontrar no universo virtual. 3) Interação que é a possibilidade de interagir com a imagem e manipulá-la como se fosse matéria.

Percebe-se que com a ajuda da informática e da robótica, a RV estende as percepções dos nossos cinco sentidos, representando mais do que o real estado das coisas. O conhecimento é construído buscando a informação e explorando um dado como se de fato ele existisse, o que traz maior motivação ao estudante, pois permite o desenvolvimento do trabalho no seu próprio ritmo, explorar em vez de deduzir, aprender de forma ativa, interagindo e facilitando uma análise global e suas inter-relações.

As aplicações da realidade virtual na educação são muitas e existe um consenso de que ajuda no processo de ensino e aprendizagem, sendo eficaz e eficiente. É difícil predizer quais os seus benefícios, pelo fato de haver vários padrões nas interfaces utilizadas. A tecnologia disponível e as limitações de custo farão com que o nível de sofisticação defina o tipo de aplicação a ser empregado.

Na educação médica cirúrgica dos países desenvolvidos, a RV tem sido empregada no ensino de anatomia e na simulação de operações, principalmente para o treinamento operatório de cirurgia video-laparoscópica, no planejamento pré-operatório e no suporte intraoperatório. As imagens de modelos virtuais têm como vantagem a possibilidade de se avaliar os órgãos tridimensionalmente, de se observar a estrutura interna do órgão com o recurso da semitransparência, de se avaliar as relações entre os órgãos com suas topografias e de se produzir visões seletivas do corpo. Além destas vantagens, não apresenta limitação de tempo de utilização.

Enfim, o estímulo da participação ativa do usuário na RV, pode atingir áreas nas quais os métodos tradicionais de ensino médico estejam falhando, principalmente para as pessoas que preferem o aprendizado visual ao verbal. Entretanto, dado o escasso conhecimento prático das aplicações das novas tecnologias, há uma predisposição em acreditar que estas não sejam a solução para nossos problemas. Por esta razão, correse o risco de utilizar soluções menos sofisticadas e que tenham uma relação custo/benefício menos favorável.

Atualmente no Brasil, somente algumas unidades de pesquisa têm desenvolvido projetos com aplicação da realidade virtual para o ensino e para o treinamento na área médica devido às dificuldades técnicas e ao alto custo. Entretanto, algu-

\footnotetext{
* Doutor em Medicina em Técnica Operatória e Cirurgia Experimental da Universidade Federal de São Paulo - Escola Paulista de Medicina (UNIFESP-EPM), Professora afiliada do Departamento de Cirurgia da UNIFESP-EPM, Pesquisadora 2C - CNPq.

** Pós-Graduando, nível Mestrado do Programa de Pós-Graduação em Cirurgia e Experimentação da UNIFESP-EPM.
} 
mas propostas estão surgindo para minimizar as dificuldades de desenvolvimento e manutenção dos sistemas e programas necessários. Assim como, recursos humanos qualificados, envolvendo a interação entre diferentes áreas do conhecimento, estão sendo preparados para a otimização e a democratização no uso desse recurso no processo ensino-treinamentoaprendizagem.

Correspondência:

Edna Frasson de Souza Montero

Alameda Espada, 134/11

06540-395 Santana do Parnaíba - SP

efsmontero.dcir@epm.br

Data do recebimento: 10/06/2003

Data da revisão: 08/07/2003

Data da aprovação: 05/08/2003 